\title{
College English Curriculum Reform in Mainland China: Contexts, Contents and Changes
}

\author{
Jiying $\operatorname{Han}^{1} \&$ Hongbiao Yin ${ }^{2}$ \\ ${ }^{1}$ School of Foreign Languages and Literature, Shandong University, Jinan, China \\ ${ }^{2}$ Faculty of Education, The Chinese University of Hong Kong, Hong Kong \\ Correspondence: Hongbiao Yin, Department of Curriculum and Instruction, Faculty of Education, Chinese \\ University of Hong Kong, Shatin, N.T., Hong Kong. Tel: 852-3943-1213. E-mail: yinhb@cuhk.edu.hk
}

Received: January 13, 2016

Accepted: January 15, 2016

Online Published: February 4, 2016

doi:10.20849/aes.v1i1.9

URL: http://dx.doi.org/10.20849/aes.v1i1.9

\begin{abstract}
In China, the latest issued national guideline for college English teaching in 2007 has set a significant agenda for college English teaching and learning in the changed context with enhanced objectives for teaching and learning, decentralised guideline for individual institution, innovated teaching and learning process and evaluation system, and particular concern for teacher professional development. This study starts with a contextual analysis of the implementation of the latest round of college English curriculum reform in mainland China, then presents an overview of the content of the new curriculum, and finally elaborates the changes brought by the reform to various aspects of college English teaching and learning. Implications and directions for future research are indicated in concluding remarks.
\end{abstract}

Keywords: college English, curriculum reform, context, content, changes

\section{Introduction}

As one of the current contexts for English-as-a-Foreign-Language (EFL), English language teaching (ELT) in China has a history. In the past few decades, China's rapid economic development and explosion in international communities under the trend of globalisation has given rise to an ever-increasing demand for English learning and utility at both national and individual levels. Therefore, China's government has made great efforts to politically and financially support the development of ELT at various educational levels. College English teaching, which makes up the majority of English learners in China, has always aroused more attention, and it has undergone the most changes and reforms ever since its official foundation. However, it has never escaped from the criticism of 'teaching-to-the-test' (Tang \& Biggs, 1996), and therefore producing 'deaf and dumb' English learners (Cheng \& Wang, 2012). As a result, debate on college English curriculum reforms has never ceased.

With the view of meeting the increased national and social demands for qualified personnel and keeping up with the pace of China's internalisation and globalisation in the new era, a new round of college English curriculum reform was planned since 2002. The reform was unveiled with the releasing of College English Curriculum Requirements (simplified as Requirements thereafter) for trial implementation in 2004 and the finalised publication of Requirements in 2007. As a significant and revolutionary step forward in the process of College English curriculum reform, Requirements 2007, with striking features such as enhanced teaching objectives and decentralised national guideline etc. when compared with previous versions of syllabuses, created a new era for college English teaching and learning in China (e.g., Wang, 2008, 2010).

The understanding of curriculum is closely related to a number of contextual factors which are key determinants of the success of a language program (Richards, 2001), and the changed curriculum definitely brings great changes for teaching and learning process. Therefore, it is necessary to question what contextual factors have initiated the reform of college English curriculum, how college English teaching and learning in China is influenced by the ever-changing context, and to what extent years of implementation and efforts made to deepening the reform have influenced the current college English teaching and learning. To address these questions, this study starts with a contextual analysis of the implementation of the latest round of college English curriculum reform, then presents an overview of the content of the new curriculum, and finally analyses the 
changes brought by the reform of college English curriculum.

\section{Context of the Curriculum Reform}

The importance of context can never be over-emphasised because curriculum is shaped by a number of contextual factors (Cornbleth, 1990). In the case of college English curriculum reform in mainland China, mixed factors of social, cultural and educational ones are frequently mentioned as key considerations (e.g., Cai, 2002, 2004; Wang, 2010).

\subsection{Social Context}

China's Reform and Open Door Policy have hastened its economic development and explosion in international communities in the past few decades, and along with the trend of globalisation, there is an increasing demand for English learning and utility at both national and individual levels. China's entry into World Trade Organisation, the accelerated process of global integration, and the increasingly frequent international exchanges have posited pressing demands for training 'composite talents' who are expected to integrate communicative skills with knowledge in specific fields. Hence, English has always been viewed as a key element in China's modernisation and development, and college graduates with strong abilities to use English in an all-round way are in great need. However, following the traditional ritual of modeling, mimicking and memorising activity in English classroom, ELT in China was compared to be 'a kettle of half-warm water that cannot be brought to the boil' (Jing, 1999), and it bears the criticism of 'teaching-to-the-test' (Tang \& Biggs, 1996) as well as producing 'deaf and dumb' English learners (Cheng \& Wang, 2012). Therefore, to improve students' communicative competence to use English for educational and professional purposes is the vital concern for current college English teaching.

\subsection{Cultural Context}

Accompanying China's increasing popularity in international economic and political stages is the changed conceptions of teaching and learning which have been traditionally shaped by Confucius heritage culture (CHC) in China's history. China's education has evolved into a hybrid of Confucian and western educational traditions. The traditionally endowed roles of teachers as authorities and models in knowledge and skills have been challenged by students who were born and exposed to the new era of highly developed information and technology. In addition, the imperative need for improved professionalism has made teaching never a simply 'teaching books' position labeled as 'spoon-feeding' method, neither has it been an 'iron rice bowl' indicating a secure and lifelong job under the educational structure reform. As for language learning, views on English learning have shifted from the excessive pursuit of passing the exams to the focus on developing students' communicative competence for practical use. Therefore, educational Chinese culture of learning in language classroom, which was featured by rote learning, model imitating, repeated practice, teacher authority and complete acceptance (Cortazzi \& Jin, 1996), has deviated the improved teaching objectives required by current times.

\subsection{Educational Context}

In China, the expansion of college enrollments on a large scale since 1999 brought about many problems. After the 3-year consecutive enrollment expansion of college from 1999 to 2001, the number of undergraduate in 2002 has doubled that of 1998, and the number of college English learners is estimated to about 24.5 million (People's Daily Online, 2011). The college English teacher-student ratio increased from 1: 50 in 1998 to 1:130 in 2001 (Dai \& Hu, 2009). The enrollment expansion of college also created employment expansion of college English teachers with bachelor's degree. A study with 341 institutions indicated that up to 2001, 72\% of college English teachers had a bachelor's degree, $21.9 \%$ had a master's degree and $0.3 \%$ had a doctor's degree (cited in Dai \& $\mathrm{Hu}, 2009)$. Therefore, the overall educational background of college English teachers is unsatisfactory compared with college teachers of specialty. In accordance with the increased number of students, a majority of college English teachers have increased teaching hours. Typically, each academic year is made up of two 17-week semesters, and the required teaching hours for college English ranges from 240 to 270 each year with a variance from 8 to 16 hours per week (Ma, 2012). Although the construction of college English teaching staff has attracted extensive attention with China's Ministry of Education's (MOE) implementation of College Teaching Quality and Teaching Reform Project in 2003, the conflict between increased demand for college English teaching and unsatisfactory educational background of EFL teachers is a pressing issue to be solved.

\section{College English Curriculum Reform Since 2002}

In compliance with the requirements of the changed context, the latest round of college English curriculum reform was implemented in two steps. It was initiated in 2002, and College English Curriculum Requirements was drawn up as official guideline in 2004 for trial implementation. In 2007, the revised College English 
Curriculum Requirements was finalised and issued. Specific requirements for college English teaching and learning stipulated by Requirement 2007 are fully formulated and described in terms of individualised learning which is based on constructivism that emphasises enabling students to construct knowledge themselves in their minds, and cognitive information processing theory which suggests enabling students to process information in a manner that best suits their cognitive style. As a revolutionary step forward in the process of College English curriculum reform, Requirements 2007 has many striking features compared with previous syllabuses. The contents and characteristics of the college English curriculum reform are summarised as follows.

\subsection{Enhanced Teaching Objectives}

In view of the development of college English curriculum, developing students' reading skills has long been emphasised. The first officially issued syllabus in the history of College English teaching, College English Teaching Syllabus (Draft) 1980, was a starting point in the history of College English curriculum formulation and revision. With the stress on reading skills, the requirements for listening, speaking and writing were proposed as supplementary practice to facilitate reading. Subsequently, Syllabus 1985 (for natural sciences) and Syllabus 1986 (for liberal sciences) grouped the five skills (reading, writing, listening, speaking and translation) into three levels with the objective of cultivating students' strong ability to read, normal ability to listen and translate and preliminary ability to write and speak. With the particular emphasis on the development of reading skills, only reading skills were fully developed. In Syllabus 1999, the objective was to develop students' great ability to read and certain abilities to listen, speak, write and translate, so that they were able to exchange information in English. Therefore, all language skills were divided into two general tiers: reading in the first tier, and listening, writing, speaking and translation in the second tier.

However, with the particular stress on developing students' overall competence, the dominant position of developing reading skills was changed with the publication of Requirements 2007. The objective of Requirements 2007 is to 'develop students' ability to use English in a well-round way, especially in listening and speaking, so that in their future studies and careers as well as social interactions they will be able to communicate effectively, and at the same time enhance their ability to study independently and improve their general cultural awareness so as to meet the needs of China's social development and international exchanges' (2007, p. 5). Developing students' communicative competence and cultural awareness are particularly stressed, and accordingly, listening and speaking abilities are put in priority. This is a distinctive difference from previous overwhelming stress on reading skills.

\subsection{Decentralised National Guideline}

It was the first time to use the term 'curriculum' rather than 'syllabus' to name a national guideline for English instruction to non-English majors. Although both curriculum and syllabus fall into the scope of course design, syllabus is perceived as a component of curriculum (Nunan, 1988; Posner, 1995). The transition of the term from 'syllabus' to 'curriculum' to name national guideline to College English education reflected the changed views towards the role that state guidance played in EFL teaching.

Taking into account the teaching resources, students' level of English upon entering university and the social demands they may face, Requirements 2007 has no longer set the requirements of national unified teaching. However, it sets three levels for undergraduate college English teaching ranging from the minimum level of 'basic requirements', to medium level of 'intermediate requirements' and advanced level of 'higher requirements'. Accordingly, 'non-English majors are required to attain to one of the three levels of requirements after studying and practicing English at college, and students with relatively higher level of English proficiency and capacity for learning are encouraged to meet higher level of requirements' (2007, p. 4). Therefore, institutions have much autonomy to choose an appropriate level as their teaching goals according to their specific circumstances. Under the guidance of the decentralised national curriculum, institutions are required to develop their own course system as a combination of comprehensive English, language skills, English for practical use, language and culture, and English of specialty in forms of either required or elective courses to meet the need of students at different levels.

\subsection{Innovated Teaching Process}

Based on the popularity of multimedia and network technology in early 21 th century, a new teaching model was under way to gear towards students' individualised and autonomous learning. This is a great improvement to replace the traditionally and purely educational model of taking the teacher as the primary part in teaching, which has been popularised since China's reform and opening-up. The existing unitary teacher-centred pattern of language teaching is substituted with 'a combination of computer- and classroom-based teaching models, which is built on modern information technology particularly network technology, so that students could facilitate their 
individualised and autonomous learning free from constrains of time and space' (2007, p. 18). The new model, which fully employs modern information technology, attaches particular importance to the centredness of students and the leading role of teachers in the teaching and learning process. Based on that, institutions are required to establish their institute-based models for the teaching of listening and speaking skills, and provide students with web-based training and teaching of listening and speaking. Reading, writing and translation courses could be conducted either in class or online. Along with these changes, teachers' face-to-face instruction is provided to guarantee the effects of students' learning.

\subsection{Multiple Evaluation System}

A new evaluation system of students' learning, which is a combination of formative assessment and summative assessment, was introduced. As a key component in College English teaching, a comprehensive, objective, scientific and accurate evaluation system is of vital importance for achievement of the teaching objectives as well as providing teachers with feedbacks. To facilitate effective monitor of students' autonomous learning, formative assessment combines students' self-assessment, peer assessment, a teacher assessment in forms of record of students performance in and outside classroom activities, online self-learning, portfolios of learning records and conducting interviews. Summative assessment consists of achievement tests and proficiency tests conducted at the closure of a teaching period. Tests are focused on evaluation of students' all-round ability to use English, and additional tests of practical listening and speaking skills are conducted along with the tests of reading, writing and translation ability. The evaluation system also includes that of teachers, namely, the evaluation of teaching process based on both students' academic performance and an overall evaluation of teachers' attitude, approaches and methods, together with the content, organisation and effects of their teaching.

\subsection{Concern about Teacher Professional Development}

Requirements 2007 takes teacher professional development into consideration by encouraging the establishment of faculty development system. It is the first time for a national guideline to put forward detailed descriptions for the aim of teacher professional development. Institutions are encouraged to build a faculty team with appropriate structure of age, educational background and professional titles, strengthen teacher training, encourage teachers to conduct teaching research to improve the quality of teaching, create conditions suitable for carrying out various forms of teaching and research activities, promote teachers' effective cooperation in teaching and research, and enable them to quickly adapt to the new teaching model. Meanwhile, institutions are enabled to reasonably arrange academic and vocational sabbatical for teachers in order to promote their continuous improvement in both teaching and academic performance.

\section{Changes Brought by the Curriculum Reform}

College English curriculum reform has been a much-debated topic in China, and Requirements 2007 has put forward great changes for college English teaching and learning in practice. Richards (2001) proposed a model, with four sources of factors, accounting for the conditions of good teaching in language program: institutional factors, teacher factors, teaching factors and learner factors. He believed that these factors should be involved in examining conditions for good teaching to take place. Following Richards' model, changes brought by the latest round of reform for institutions, teaching, teachers and learners are analysed.

\subsection{Changes of the Organisational Culture and Teaching Philosophy in Institutions}

The organisational culture is a key factor to be considered in institutions. The basic concept of organisational culture is the management structure for which Davidson and Tesh (1997) distinguished two types: the mechanistic model characterised by a bureaucratic approach to organising collective activities and the organic model valuing flexibility and adaptability. However, they acknowledged that most language programmes have mixed features of both organic and mechanistic model. In China, college English teaching is implemented under the direct guidance of MOE, and previous national syllabuses have been observed as direct guidelines for college English teaching by institutions throughout the country. As the new Requirements decentralised the decisive role in teaching to individual institution, institutions start to take full responsibilities for the overall process of developing, implementing and evaluating their individualised and institute-based curriculum as a response to the request of formulating a scientific, systematic and individualised teaching syllabus to guide ELT in individual institution. Besides, in accordance with the proposed teaching model in Requirements 2007, institutions have taken great effort to increase their investment in improving current teaching facilities by establishing increasing numbers of autonomous learning centres, network language laboratories and multimedia classrooms to aid and facilitate college English teaching and learning in and outside classrooms.

However, the implementation of the innovated teaching does not go smoothly when taking into account the 
teaching resources, students' level of English upon entering university and the social demands they may face. In response, level-based teaching was adopted by a number of institutions in accordance with the three levels set by Requirements since the early 2000s. Along with the level-based instruction, in-class instructions are accompanied by students' self-learning for extra hours with the advantage of websites and autonomous learning centres to cultivate their learning autonomy in accordance with the combination of computer-based and classroom-based multimedia teaching models. Moreover, based on level-based instruction, college English teaching is further deepened with continuous endeavors made by institutions to guarantee their English teaching quality and improve students' all-round English communicative abilities. With the emphasis on maximally cultivating students' communicative competence in listening and speaking, trials have been made to explore the possibilities and feasibilities of dividing the traditional Comprehensive College English course into different modules, such as Listening and Speaking course and Reading and Writing course, by giving equal importance to individual course. This new teaching model emerged as a newborn outcome of the reform to meet the pressing need of cultivating students' communicative competence, and it starts to gain more popularity in recent years. Constructivism, Krashen's monitor model of second language development, synthesising theory model in management psychology, and interaction between language input and output have provided theoretical basis for the new teaching model (Feng \& Wu, 2009; Gao, Gan, \& Liu, 2009; Hu, 2009). However, the lack of empirical research on the implementation of the new teaching model indicates a long way to go for further evaluation and generalisation of the model.

\subsection{Changes of Teaching}

\subsubsection{The Changed Teaching Approach}

The implementation of college English curriculum reform facilitates the transition from traditional grammar-translation approach to communicative language teaching approach. The history of particular emphasis on reading skills has framed China's traditional college English teaching as grammar-oriented and teacher-centred, and the combination of grammar-translation method (GTM) and audio-lingual method (ALM) constitutes the traditional approach of ELT in China. Accordingly, the teaching contents were organised around language points, and ELT in class relied on the process of English-Chinese, and Chinese-English translation to a greater extent. College English teachers were no more than translators to pass on grammar knowledge of English in a simple sequence of identifying, explaining, practicing, and summarising the language points in class. Students taught by traditional approach have developed a good mastery of large vocabulary and grammar knowledge. However, they were found incompetent for communication because the deep-rooted notion of over-emphasised reading and writing skills de-emphasised their development of practical listening and speaking skills for communication. Therefore, ELT in China has been widely criticised for being inefficient and test-oriented, and producing 'deaf and dumb' English learners who were grammatically competent but communicatively incompetent (Cheng \& Wang, 2012).

To address these problems, Communicative Language Teaching (CLT) was introduced into China in early 1990s. However, labeled as task-based and student-centred, CLT has failed to receive widespread attention or support initially due to the lack of fundamental change in conceptions of effective teaching and learning among domestic English language teachers and learners $(\mathrm{Hu}, 2002)$. With the belief that CLT would be the best solution for students' low communicative competence, the MOE launched a top-down movement to promote the application of CLT in China through syllabus design and materials development since the late 1990s (Adamson \& Morris, 1997; $\mathrm{Hu}, 2002$ ). A new innovation made by new Requirements is the emphasis on developing students' communicative skills especially listening and speaking skills. It is the first time to put the development of listening and speaking skills as much important as, or even more important than, that of reading and writing skills. Hence, CLT starts to exert significant influence on college English teaching.

\subsubsection{Changed Form of Assessment}

The importance of examination at various educational levels in China derives from the philosophy of Chinese culture of examination which believes that success in examination is the only path to change one's social status and achieve social mobility. The metaphor of 'an army crossing a one-log bridge' is a good demonstration of the weight of examination which has not decreased for centuries in Chinese curriculum. In consideration of the traditional exam-oriented culture, the introduction of formative assessment in college English teaching marks a fundamental change from the excessive pursuit of a higher proportion of those who pass the exams towards the shifted focus on the learning process in language teaching and learning. Based on the combination of formative and summative assessment advocated by Requirements 2007, a multiple evaluation system is employed in college English teaching by integrating self-assessment, peer-assessment and teacher-assessment into formative 
Assessment. To guarantee the appropriateness of formative assessment, institutions are decisive for developing their individualised criteria in details and the ratio of formative and summative assessment in students' end-of-term scores.

As a national summative assessment for English proficiency of non-English majors in China, reforms on College English Test (CET) band 4 and band 6 have taken place since the new CET test syllabus was published in 2006. Under the guideline of the new Requirements, the part of grammar and vocabulary was eliminated, and the proportion of listening comprehension was increased to facilitate the implementation of CLT in teaching practice. Along with that, oral test was suggested to take based on good performance in written exam. Moreover, the traditional certificate with a general rating scales distinguishing failed, passed, good and excellent has been substituted for a test report with an overall score and itemised scores in listening, reading, and writing ranging from 220 to 710 . The changed form of test report is helpful for teachers and students to diagnose their teaching and learning in practice. Furthermore, the traditional way of test taking, a nation-wide written test, is under the transition towards a computer-based test generated by a large-scale examination database. To facilitate the implementation and generalisation of computer-based test taking, investments have been dramatically increased in database research and development as well as the improvement of testing facilities.

\subsection{Changes of Teachers}

\subsubsection{Changed Roles of Teachers}

The curriculum reform intends the changed roles of teachers in classroom instruction and the overthrow of that in traditional teaching. The innovated teaching requires teachers to become an organiser, facilitator and instructor for students' learning rather than dominator and controller for traditional teaching (Dai \& Hu, 2009). The changed roles of teachers has brought about great changes and challenges for college English teachers among whom a majority is deeply influenced by $\mathrm{CHC}$ which projects teachers to be authorities and models in knowledge and skills.

As a popular Chinese saying goes, 'To give students a bowl of water, the teacher must have a full bucket of water to dispense', CHC portrays teachers to be unquestionably knowledgeable, and having deep knowledge ranked top among qualities for a good teacher (Cortazzi \& Jin, 2001). In the case of college English teaching, to meet students' highly increased need of using English for practical purpose, college English teachers are expected to have a high level of English language proficiency and a strong sociolinguistic competence with cultural background of English-speaking countries. However, ELT for non-English majors in China is conducted by indigenous Chinese teachers most of whom have learned English in China without accesses to or familiarity with English native speakers or communities. Therefore, most college English teachers are not competent enough in language proficiency and communicative competence. Besides, the changed roles of teachers challenge teacher authority which is deeply rooted in CHC and reflected both in and outside classrooms. Under CHC collectivism, teacher-student relation is characterised by hierarchical social relationships, and individuals are supposed to conform to uniform standards of behaviours (Ho, 2001). Therefore, as the saying suggests, 'a teacher for one day, a father for the whole life', Chinese students are trained to show respect to teachers and be obedient and passive recipients of knowledge at early age. However, this traditionally and culturally framed conceptions of teacher authority and teacher centredness is contradictory to currently advocated student centredness. With the shifted focus of teaching towards learners, student centredness encourages students to construct knowledge through active learning, cooperative learning and inductive learning. Therefore, teachers are supposed to be a facilitator, organiser, assessor, prompter, participant and information source in a communicative classroom.

In view of the changed roles of teachers in ELT, it is urgent for college English teachers to develop their professionalism. Although teachers' professional development has been taken into account by Requirement 2007, the onerous teaching and research load make the 'academic and vocational sabbatical' merely an illusion for most college English teachers. Although recently the China Scholarship Council (CSC) has provided increasing opportunities for Chinese teachers in high education to study abroad, as the expert evaluation of applicants of CSC sponsorship has strict criteria for professional rank and research output, only a very slight number of college English teachers could meet the application criteria and very fewer applicants have been successfully sponsored by CSC to go overseas for further study. Therefore, the most significant and common way for college English teachers to pursue their professional development is through domestic study and training at various levels.

\subsubsection{Increased Professional and Academic Pressures for Teachers}

The ever-increasing requirements for teaching and research of college English teaching have initiated much pressure for college English teachers both professionally and academically, and teaching and research have 
become the main workloads for college English teachers.

First of all, the implementation of CLT which requires the integration of developing grammatical competence, sociolinguistic competence, discourse competence and strategic competence for overall communicative competence (Canale \& Swain, 1980) creates great challenges for college English teachers among whom a majority was taught by and teaching with traditional approaches. In addition, as the complexity in language learning lies in the integration of learning another culture (Gardner, 2007), language teachers are supposed to take into account a variety of socio-cultural and affective factors which are determinant for the success of language learning. As non-native English teachers who are merely exposed to native speakers and communities, college English teachers are facing additional pressures and challenges when they teach English to students who have limited access to the target language and culture outside classroom.

Moreover, research engagement has become increasingly important for college English teachers. Although college English teachers have developed stronger awareness of conducting research these years, their overall research abilities are generally weak compared with teachers of speciality. A recent survey of college English teachers in ten domestic universities has found that 87.5 percent of assistants and lecturers have almost never participated in any research work. Additionally, college English teachers were found to employ simple and unitary method in research, and lack of theoretical knowledge and motivation of doing research (Zhang \& Wang, 2008). Factors affecting the research ability of college English teachers have been identified as the instrumentalisation and commercialisation of English language, the metaphysicisation of English language research and the difficulties in making research results published (Wu \& Zhang, 2011).

The importance of research engagement also lies in its significant role in promotion. As one of the key criteria for promotion, research output is measured by the number of publications of research papers as well as the participation in research projects at various levels, and usually institutions have their individual quantitative and qualitative requirements for research publications and participation. However, the fulfillment of all requirements does not guarantee the promotion to higher rank as it only serves as a prerequisite for applying for promotion because of the capped number of academics at each level. In addition to those criteria, some institutions set additional criterion on educational background for promotion. For example, considering the general educational background of in-service college English teachers, a doctor's degree is required for promotion from lecturer to associate professor. This criterion is obviously helpful to stimulate college English teachers to improve their professionalism by pursuing higher degrees. As a study indicates, the proportion of college English teachers with a doctor's degree has reached from $0.3 \%$ in 2001 to $1.2 \%$ in 2008 (Dai \& Hu, 2009). However, to gain the entry to the limited position of doctor's-level study, the competition, pressure and workload for college English teachers have been intensified.

\subsection{Changes of Learners}

Cortazzi and Jin (1996) proposed the notion of 'culture of learning' as a cultural approach indicating the existence of culturally-rooted assumptions underlying the process of teaching and learning in Chinese society. This approach was especially employed in studies of teaching and learning process in language classroom. Following this approach, early studies revealed that the Chinese culture of learning in language classroom was featured as rote learning, model imitating, repeated practice, teacher authority and complete acceptance. These features echoed the results of many other studies in which the Chinese learners were generally found passive in learning, lacking in creativity, interaction and questioning spirit. With regard to College English class which has always been a target of criticism from both domestic and western learners, features as excessive teacher-centredness, lack of communication and ignored interactive were also found in classroom observations (Coratzzi \& Jin, 1996). Interpretation and explanation of features about teaching and learning process in college English class are related to Chinese conceptions of learning and teaching shaped by CHC. The belief of Chinese teachers and learners in teachers' role of modelling and authorities in knowledge and skills has got Chinese learners accustomed to the way of modelling, mimicking and memorising in language learning. The exam-oriented English learning experience in middle school has brought many college students mistakenly believed that college English learning is largely a matter of learning long list of vocabulary (Jin \& Cortazzi, 2006).

However, with the innovations advocated by college English curriculum reform, the changed context prompts college students to adapt themselves to new ways of college English teaching and learning. The innovated computer- and classroom-based college English teaching model, which attaches high importance to individualised teaching and autonomous learning, has put forward high requirements for the development of students' autonomy. Although learner autonomy has been advocated in college English learning since the late 
1990s in China, studies before 2004 have been mainly devoted to the introduction of the theory and the exploration of possible models in college English teaching (Liu \& Dong, 2012). With the formal implementation of the combined teaching model, the emphasis on learner autonomy through self-directed learning expects students to take responsibilities for their own learning (Holec, 1981) and be reflectively involved in planning, implementing, monitoring and evaluating learning (Little, 2007). All these changed roles of students in learning together with learner-centredness imposed by CLT fundamentally revolutionised Chinese students' role and conceptions of language learning, and brought about great challenges and impact on those who have traditionally developed the habit of passive learning.

Moreover, the particular stress on developing students' communicative competence of the reform provides considerable opportunities to turn college English teaching and learning around. For many years, college English teaching and learning has been criticised for producing 'deaf and dumb' English learners due to its uneven stress on reading skills at the expense of listening and speaking skills. However, the new Requirements strongly suggests teacher-student and student-student interactions in a collaborative way of learning by combining cognition and social context under the framework of social cognitive learning theory. Therefore, college English teaching and learning in classroom is mainly organised and conducted in students' peer groups, through which students' interests and critical thinking are expected to develop. The changed classroom context brings huge impact on Chinese students learning mentally and practically. Additionally, the increased number of newly published textbooks which are focused on communicative competence, and the accompanying access to online language learning centres provided by publishers have enriched the content and forms of college English learning materials.

\section{Concluding Remarks}

College English curriculum reform is imperative considering the changed social, cultural and educational context in mainland China, and debate on college English curriculum reform has never ceased due to the imbalance between the effort and support made by government and learners' language incompetence resulting from traditionally shaped teaching and learning process. As a revolutionary step forward in the process of college English curriculum reform, Requirements 2007 has set a significant agenda for college English teaching and learning in the changed context with enhanced objectives for teaching and learning, decentralised guideline for individual insititution, innovated teaching and learning process and evaluation system, and particular concern for teacher professional development. This study provides a well understanding of the process of the latest round of college English curriculum reform and the great changes and severe challenges the implementation of the reform has brought about to college English teaching and learning process. Therefore, the study contributes to the existing literature in the area of language curriculum reform not only in China but also other EFL contexts. It serves as a particular reference to EFL teaching and learning in non-English speaking countries especially those deeply influenced by CHC. In addition, the understanding of various changes brought by the curriculum reform in all aspects will facilitate the spread of its positive impacts and enrich the practical experience in implementing the reform in this new era.

The significance of the study also lies in its implications in a number of areas. First of all, the study implies the significance of contextual factors in the initiation of a curriculum reform as they helps to prompt and target the reform. So a number of social, cultural and educational factors should be taken into account to launch a reform (Cornbleth, 1990). Secondly, the study indicates the role of the organisational input of institutions in the overall process of developing, implementing and evaluating their individualised and institute-based curriculum. Considerations of factors specific to circumstances of institutions contribute to the characteristics and uniqueness of individualised and institute-based curriculum. In addition, the study strengthens the importance of developing and enhancing a number of related aspects such as teacher development, philosophies and conceptions of teaching and learning, teaching facilities etc., along with the implementation of curriculum reform. Last but not least, this study may also have practical implications for researchers and administrators, especially those on whom decisive role is imposed in curriculum reform, to take effective measures to overcome the challenges and deepen the reform in practice.

So far the latest round of college English curriculum reform in mainland China has attracted increasing interests of researchers, and the study indicates possibilities of directions for future research. On one hand, as a ground work to provide information for the initiation and implementation of the curriculum reform, it paves the path for future studies to further explore the continuation of the reform, which is one of the three phases of Fullan's (2007) change process model. It also foreshadows future concerns about outcomes of the reform to provide us practical and empirical information about the reform with first-hand data and evidence. On the other, as the study provides an overview of the reform, future studies are highly expected to go further for in-depth information of the reform. 
For example, what has been done in institutions to implement the curriculum reform? What challenges have been presented to teachers and students in implementing the new Requirements? What have been done to overcome those challenges? What have been some of the good results and lessons learned? All those related issues are expected to be addressed by future studies.

\section{References}

Adamson, B., \& Morris, P. (1997). The English curriculum in the People's Republic of China. Comparative Education Review, 41, 3-26. http://dx.doi.org/10.1086/447413

Cai, J. (2002). On the reform of college English curriculum design in key universities. Foreign Language World, $5,10-16$. (in Chinese)

Cai, J. (2004). On the basic principles of the teaching requirement for college English. Foreign Languages and Their Teaching, 1, 18-22. (in Chinese)

Canale, M., \& Swain, M. (1980). Theoretical bases of communicative approaches to second language teaching and testing. Applied Linguistics, 1, 1-47. http://dx.doi.org/10.1093/applin/I.1.1

Cheng, A., \& Wang, Q. (2012). English language teaching in higher education in China: A historical and social overview. In J. Ruan, \& C. B. Leung (Eds.), Perspectives on teaching and learning English literacy in China (pp. 19-33). Dordrecht: Springer.

Compilation Committee of public English teaching materials for college of science. (1980). English teaching syllabus (draft). Beijing: People's Education Press.

Cornbleth, C. (1990). Curriculum in context. London: Falmer Press.

Cortazzi, M., \& Jin, L. (1996). Cultures of learning: Language classrooms in China. In H. Coleman (Ed.), Society and the language classroom (pp. 169-206). Cambridge: Cambridge University Press.

Cortazzi, M., \& Jin, L. (2001). Large Classes in China: 'Good' teachers and interaction. In D. Watkins, \& J. Biggs (Eds.), Teaching the Chinese learner: Psychological and pedagogical (pp. 115-134). Hong Kong: CERC.

Dai, W., \& Hu, W. (2009). Research on the development of foreign language education in China (1949-2009). Shanghai: Shanghai Foreign Language Education Press. (in Chinese)

Davidson, J., \& Tesh, J. (1997). Theory and practice in language program organization design. In M. A. Christison, \& F. Stoller (Eds.), A handbook for language program administrators (pp. 177-197). Burlingame, CA: Alta Books.

Feng, X., \& Wu, J. (2009). Management psychology-guided implementation of stratified and sub-curriculum-oriented college English teaching: A synthesizing theory model-based empirical study. Journal of Fujian Medical University (Social Science Edition), 10(4), 39-43. (in Chinese)

Fullan, M. (2007). The new meaning of educational change (4th ed.). New York: Teachers College Press.

Gao, Y., Gan, L., \& Liu, X. (2009). An introduction to college English module-specific class teaching model. Journal of Huazhong Agricultural University (Social Sciences Edition), 4, 94-98. (in Chinese)

Gardner, R. C. (2007). Motivation and second language acquisition. Porta Linguarum, 8, 9-20.

Herrera, S. G., \& Murry, K. G. (2005). Mastering ESL and bilingual methods: Differentiated instruction for culturally and linguistically diverse (CLD) students. Pearson: Allyn and Bacon.

Ho, I. T. (2001). Are Chinese teachers authoritarian? In D. Watkins, \& J. Biggs (Eds.), Teaching the Chinese learner (pp. 277-300). Hong Kong: CERC.

Holec, H. (1981). Autonomy and foreign language learning. Council of Europe, Oxford: Pergamon.

$\mathrm{Hu}, \mathrm{D}$. (2009). The feasibility of teaching college English on different levels: A study based on the college English teaching reform of China university of Geosciences. Shandong Foreign Language Teaching Journal, 1, 62-65. (in Chinese)

Hu, G. (2002). Potential cultural resistance to pedagogical imports: The case of communicative language teaching in China. Language Culture and Curriculum, 15, 93-105. (in Chinese)

Little, D. (2007). Language learner autonomy: Some fundamental considerations revisited. International Journal of Innovation in Language Learning and Teaching, 1, 14-29. http://dx.doi.org/10.2167/illt040.0

Liu, Y., \& Dong, B. (2012). The exploration of the practice-oriented college English teaching and learning 
reform by reviewing the studies of the English related autonomous learning development in China. Foreign Languages in China, 2, 72-80. (in Chinese)

Ma, W. (2012). Factors affecting the motivation of TEFL academics in higher education in China. Shanghai: Fudan University Press.

Nunan, D. (1989). Designing tasks for the communicative classroom. Cambridge: Cambridge University Press.

Posner, G. J. (1995). Analyzing the curriculum. New York: McGraw-Hill.

Richards, J. C. (2001). Curriculum development in language teaching. Cambridge: Cambridge University Press.

Richards, J. C., \& Rodgers, T. S. (2001). Approaches and methods in language teaching. Cambridge: Cambridge University Press.

Tang, C., \& Biggs, J. (1996). How Hong Kong students cope with assessment. In D. Watkins, \& J. Biggs (Eds.), The Chinese learner: Cultural, psychological and contextual influences (pp. 159-182). Hong Kong: CERC.

The higher education department of the Ministry of Education. (2004). College English curriculum requirements (for trial implementation). Beijing: Foreign Language Teaching and Research Press.

The higher education department of the Ministry of Education. (2007). College English curriculum requirements. Beijing: Tsinghua University Press.

The revision group of college English syllabus. (1986). College English teaching syllabus (for undergraduate of science and arts). Shanghai: Shanghai Foreign Language Education Press.

The revision group of college English syllabus. (1999). College English teaching syllabus (revised). Shanghai: Shanghai Foreign Language Education Press.

Wang, S. (2008). On the revision of 'College English Curriculum Requirements'. Foreign Languages in China, 1, 4-10. (in Chinese)

Wang, S. (2012). On deepening the reform in college English teaching in China. Foreign Languages in China, 2, 4-20. (in Chinese)

Wu, Y., \& Zhang, Y. (2011). Reflections on improving the research ability of foreign language teachers - based on the articles published in foreign language world in the past ten years. Theory and Practice of Education, 31(8), 36-39. (in Chinese)

Zhang, H., \& Wang, H. (2008). Survey and study of scientific research of foreign languages teachers in University. Theory and Practice of Education, 28(12), 23-25. (in Chinese)

\section{Copyrights}

Copyright for this article is retained by the author(s), with first publication rights granted to the journal.

This is an open-access article distributed under the terms and conditions of the Creative Commons Attribution license (http://creativecommons.org/licenses/by/3.0/). 